\title{
Design of controlled release systems for THEDES-Therapeutic deep eutectic solvents, using supercritical fluid technology
}

\author{
Ivo M. Aroso ${ }^{a, b}$, Rita Craveiroc, Ângelo Rochad ${ }^{\mathrm{d}}$, Madalena Dionísioc ${ }^{c}$, Susana Barreiros ${ }^{c}$, \\ Rui L. Reis ${ }^{a, b}$, Alexandre Paiva ${ }^{c}$, Ana Rita C. Duarte ${ }^{a, b, *}$ \\ a 3B's Research Group- Biomaterials, Biodegradable and Biomimetic, University of Minho, Headquarters of the European Institute of Excellence on Tissue \\ Engineering and Regenerative Medicine, Avepark 4805-017 Barco, Guimarães, Portugal \\ b ICVS/3B's PT Government Associated Laboratory, Braga/Guimarães, Portugal \\ c REQUIMTE/CQFB, Departamento de Química, Faculdade de Ciências e Tecnologia, Universidade Nova de Lisboa, 2829-516 Caparica, Portugal \\ d IBB - Institute for Bioengineering and Biosciences, Department of Bioengineering, Instituto Superior Técnico, Universidade de Lisboa, Av. Rovisco Pais 1, \\ 1049-001 Lisboa, Portugal
}

\section{A R T I C L E I N F O}

\section{Article history:}

Received 30 March 2015

Received in revised form 19 June 2015

Accepted 20 June 2015

Available online 30 June 2015

\section{Keywords:}

Therapeutic deep eutectic solvents

Supercritical carbon dioxide

Drug delivery systems

Biodegradable polymers

Ibuprofen

\begin{abstract}
A B S T R A C T
Deep eutectic solvents (DES) can be formed by bioactive compounds or pharmaceutical ingredients. A therapeutic DES (THEDES) based on ibuprofen, a non-steroidal anti-inflammatory drug (NSAID), and menthol was synthesized and its thermal behavior was analyzed by differential scanning calorimetry (DSC). A controlled drug delivery system was developed by impregnating a starch:poly- $\varepsilon$-caprolactone polymeric blend (SPCL 30:70) with the menthol:ibuprofen THEDES in different ratios (10 and $20 \mathrm{wt} \%$ ), after supercritical fluid sintering at $20 \mathrm{MPa}$ and $50^{\circ} \mathrm{C}$. The morphological characterization of SPCL matrices impregnated with THEDES was performed by scanning electron microscopy (SEM) and microcomputed tomography (micro-CT). Drug release studies were carried out in a phosphate buffered saline. The results obtained provide important clues for the development of carriers for the sustainable delivery of bioactive compounds.
\end{abstract}

(c) 2015 Elsevier B.V. All rights reserved.

\section{Introduction}

Deep eutectic solvents (DES) have been presented as alternative solvents for a variety of applications, similarly to the developments observed with ionic liquids (ILs) in the early 90's (Abbott et al., 2004; Paiva et al., 2014; Pena-Pereira and Namiesnik, 2014). DES present, however, two major advantages that overcome the limited applicability of ILs. DES, and particularly natural deep eutectic solvents (NADES), are produced from naturally occurring molecules and have therefore inherent low toxicity (Dai et al., 2013). Additionally they are formed by combining two or more compounds that are solid at room temperature, which upon mixing at a particular composition become liquid.

The development of therapeutic deep eutectic solvents (THEDES) is a field of research that has not been extensively explored. Stott and co-workers reported that ibuprofen formed eutectic mixtures with different terpenes that were shown to

\footnotetext{
* Corresponding author at: 3B's Research Group-Biomaterials, Biodegradables and Biomimetics, University of Minho, AvePark, Zona Industrial da Gandra, 4805017 Barco, Portugal. Fax: +351 253510909.

E-mail address: aduarte@dep.uminho.pt (A.R.C. Duarte).
}

promote enhanced skin permeation. It has also been reported that DES can dissolve model drugs, increasing their solubility, permeation and absorption (Stott et al., 1998). The enhancement of the permeation of THEDES has been demonstrated by Wang et al. (2014). The permeation of the lidocaine:ibuprofen system can be finely tuned depending on the molar ratio of the two components, allowing the development of tailor-made, transdermal drug delivery systems (Wang et al., 2014). Tuntarawongsa and Phaechamud (2012a,b) reported on the preparation of a DES with therapeutic properties, consisting of a mixture of menthol and camphor with dissolved ibuprofen. DES dissolved considerable higher amounts of ibuprofen when compared to water. With the addition of a polymer, a polymeric eutectic drug delivery system was formed (Tuntarawongsa and Phaechamud, 2012b). The same behavior was observed by Morrison et al. (2009) who studied the solubilisation of benzoic acid, danazol, griseofulvin, AMG517 and itraconazole in urea:choline chloride and malonic acid:choline chloride DES. Bica et al. (2012) reported on the synthesis of new therapeutic ILs, namely tetrabutylphosphonium ibuprofenate and ephedrinium ibuprofenate and on the controlled release of these ILs from porous silica particles. The possibility to couple a THEDES with a second component, particularly a polymer, and to 
synthesize bioactive eutectic systems opens a broad spectrum of future developments in pharmaceutical and biomedical applications of these systems. The doping of biopolymers with THEDES is a new strategy for the delivery of the therapeutic agent. Biodegradable polymers made from renewable resources are an important innovation in materials science (Malafaya et al., 2007; Mano et al., 2007). Starch-based polymers in particular have been studied for a wide range of applications including the development of controlled drug delivery systems (Balmayor et al., 2009; Lu et al., 2009; Reis et al., 2008; Silva et al., 2004). Their natural origin, together with their mechanical properties and biocompatibility, are behind the potential of starch-based materials in the biomedical field (Marques et al., 2002).

The combination of THEDES, biodegradable natural based polymers, and supercritical carbon dioxide $\left(\mathrm{scCO}_{2}\right)$ is a viable alternative for the production of drug delivery systems. The use of $\mathrm{scCO}_{2}$ for the development of enhanced biomaterials for pharmaceutical and/or biomedical applications has been reported in different reviews (Duarte et al., 2009a,b; Knez et al., 2011; Salerno and Pascual, 2015; Zhang et al., 2014). $\mathrm{CO}_{2}$ is the most commonly used solvent at supercritical conditions due to its low critical parameters $\left(T_{\mathrm{C}}=31.1^{\circ} \mathrm{C}\right.$ and $\left.P_{\mathrm{C}}=73.8 \mathrm{bar}\right)$ and to the fact that it is environmentally benign, non-toxic, non-flammable, non-corrosive, readily available and inexpensive. Supercritical fluid sintering was proposed by Singh et al. (2010) for the preparation of highly porous and interconnected structures, under mild conditions. The supercritical sintering technique, similarly to supercritical fluid foaming, relies on the plasticizing effect of $\mathrm{CO}_{2}$, which reduces the glass transition temperature $\left(T_{\mathrm{g}}\right)$ of the polymer. In the case of sintering, polymeric particles are softened and fused together creating a three dimensional (3D) structure (Alves et al., 2012). Supercritical fluid sintering is a technique which relies on the decrease of the $T_{\mathrm{g}}$ of the polymer (Duarte et al., 2013). The softening of the polymer under a $\mathrm{CO}_{2}$ atmosphere allows the sintering of the particles, promoting their adhesion while leaving empty pores inside the formed structure. Supercritical fluid sintering has been described in the literature for the preparation of different scaffolds, particularly for tissue engineering, and it is particularly attractive due to the mild operating conditions, which allow the processing of thermolabile substances (Bhamidipati et al., 2013; Singh et al., 2010). The main objective of this work was the development of a controlled delivery system based on a starch polymer blend impregnated with menthol:ibuprofen THEDES, obtained by supercritical fluid sintering.

\section{Materials and methods}

\subsection{Materials}

The reagents used in the preparation of THEDES were menthol ( $\geq 98 \%$, CAS 89-78-1, Sigma) and ibuprofen, which was obtained from ibuprofen sodium salt (98\%, CAS 31121-93-4, Sigma). A $50 \mathrm{mg} / \mathrm{mL}$ solution of this compound in distilled water was prepared, and the $\mathrm{pH}$ was adjusted to $1-2$ by adding small amounts of a solution of hydrochloric acid ( $1 \mathrm{M})$ (36.5-38\%, CAS 764-01-0, Scharlau). The two compounds react, yielding ibuprofen in its acid form, and sodium chloride. Ibuprofen is extracted with dichloromethane ( $\geq 99.8 \%$, CAS $75-09-2$, Fluka) that is subsequently subjected to drying with sodium sulphate, filtration and evaporation of the solvent under reduced pressure until a fine white powder is obtained. The purity of the obtained ibuprofen was accessed by GC and NMR to a value of $>98 \%$. The polymer used in this work was a commercial blend of corn starch (70 wt\%) with poly- $\varepsilon$-caprolactone (PCL; $30 \mathrm{wt} \%$ ), henceforth designated SPCL, in granular form, obtained from Biocycle. Carbon dioxide $(99.998 \mathrm{~mol}$ $\%$ ) was supplied by Air Liquide. Phosphate buffered saline (PBS) was prepared from Phosphate buffered saline tablets (Sigma) as indicated. One tablet is dissolved in $200 \mathrm{~mL}$ of deionized water, yielding a $0.01 \mathrm{M}$ phosphate buffer, $0.0027 \mathrm{M}$ potassium chloride, $0.137 \mathrm{M}$ sodium chloride, $\mathrm{pH} 7.4$ solution, at $25^{\circ} \mathrm{C}$. All chemicals, with the exception of ibuprofen, were used without any further purification.

\subsection{THEDES preparation}

The menthol:ibuprofen THEDES was prepared according to previous reports (Carriazo et al., 2012; Russ and Konig, 2012; Stott et al., 1998), in a 3:1 molar ratio eutectic mixture. The compounds were weighted and mixed. The solid mixture was heated up to $40^{\circ} \mathrm{C}$ until it became a clear liquid. Following the procedure of Stott et al., (1998), the mixture was stored at $-20^{\circ} \mathrm{C}$ until further use.

\subsection{Characterization}

\subsubsection{Water content-Karl Fischer titration}

The water content of the THEDES was determined by Karl Fischer titration, using an $831 \mathrm{KF}$ Coulometer with generator electrode without diaphragm. The water content values given are an average of at least three measurements.

\subsubsection{Thermal properties-differential scanning calorimetry (DSC)}

DSC analysis was performed on a Q2000 isothermal differential calorimeter (TA Instruments, Tzero ${ }^{\mathrm{TM}}$ DSC technology). The samples were packed in a TA aluminum pan. For samples of menthol and ibuprofen, DSC data were collected between $-90^{\circ} \mathrm{C}$ and $120^{\circ} \mathrm{C}$, at a rate of $10^{\circ} \mathrm{C} / \mathrm{min}$. In the case of the $3: 1$ menthol: ibuprofen mixture, the DSC analysis was performed between $-10^{\circ} \mathrm{C}$ and $120^{\circ} \mathrm{C}$, at a rate of $1^{\circ} \mathrm{C} / \mathrm{min}$.

\subsection{Dissolution studies}

For the dissolution studies, approximately $65 \mathrm{mg}$ of $3: 1$ menthol:ibuprofen was weighed and immersed in $20 \mathrm{~mL}$ of PBS. Samples of $0.5 \mathrm{~mL}$ were withdrawn at $5,15,20,30,4560,120$ and $180 \mathrm{~min}, 5,7$ and $24 \mathrm{~h}$, and each sample was replaced by an equal amount of fresh PBS. The dissolution tests were also carried out with ibuprofen in the solid form. The same mass of ibuprofen present in $65 \mathrm{mg}$ of THEDES was used, which corresponded to approximately $20 \mathrm{mg}$. The samples dissolution was quantified by UV-vis spectroscopy at $265 \mathrm{~nm}$ in a microplate reader (BIO-TEK, SYNERGY HT). The results presented are an average of three measurements. The cumulative mass of drug released was determined taking into consideration the replacement of aliquots with fresh medium and the dilution derived from the addition of fresh buffer.

A calibration curve for ibuprofen (correlation coefficient of 0.99996) was obtained using standards prepared with the following concentrations: 0 (blank), 0.05, 0.1, 0.2, 0.5 and $1 \mathrm{mg} /$ $\mathrm{mL}$. A calibration curve for ibuprofen (correlation coefficient of 0.99999) was also built using the same concentrations of 3:1 menthol:ibuprofen.

\subsection{Supercritical fluid sintering}

SPCL in granular form was milled in an ultra-centrifugal mill (Retsch, ZM 200). Appropriate amounts of SPCL in powder form and of THEDES were weighed and mixed to yield SPCL mixtures with 10 and 20 wt.\% of 3:1 menthol:ibuprofen. The mixtures were homogeneous. SPCL in the same amount as used to prepare SPCLTHEDES mixtures was used as control. Another control was prepared by mixing SPCL powder with ibuprofen also in powder form. In this case, the amount of ibuprofen was the same as used in 
the SPCL-THEDES mixture with 10\% THEDES. The samples were loaded onto a stainless steel mold and were placed in the highpressure vessel. The reactor was pre-heated in a thermostatic water bath at $50{ }^{\circ} \mathrm{C} . \mathrm{CO}_{2}$ was pressurized with a high pressure liquid pump (Haskel MCPV-71, USA), until the desired pressure was reached. The samples were sintered with $\mathrm{scCO}_{2}$ at $20 \mathrm{MPa}$ and $50^{\circ} \mathrm{C}$, for $2 \mathrm{~h}$. The vessel was then slowly depressurized and the sample recovered.

\subsection{Morphological characterization}

\subsubsection{Scanning electron microscopy (SEM)}

SEM was used to analyze the surface morphology and the porosity of the matrices. The observation of the cross-sections of the samples was done after fracturing the matrix with liquid nitrogen. All samples were sputter-coated with gold before analysis. Micrographs were acquired on a SEM JSM-6010LV (JEOL, Japan).

\subsubsection{Micro-computed tomography (micro-CT)}

Micro-CT was used to evaluate the porosity and pore size of the 3D structures obtained. The images were acquired on a highresolution micro-CT SkyScan 1072 scanner (Skyscan, Belgium) using a voltage of $40 \mathrm{kV}$ and a current of $248 \mu \mathrm{A}$. After image acquisition the noise was reduced with nRecon software. CT Analyser $^{\circledR}$ software (SkyScan, Belgium) was used to obtain representative data sets of the samples and converting them into 2D images.

\subsection{Release studies}

SPCL-THEDES matrices were immersed in $20 \mathrm{~mL}$ of PBS, at $37^{\circ} \mathrm{C}$. Aliquots of $0.5 \mathrm{~mL}$ were withdrawn at predetermined time intervals and replaced by an equal amount of fresh medium. Aliquots were analysed by UV-vis spectroscopy, similarly to the dissolution studies. The $\mathrm{pH}$ of each solution was also measured in order to determine the effect of release on the acidity of the medium.

\section{Results and discussion}

\subsection{Preparation of THEDES}

As referred in Section 2, the 3:1 menthol:ibuprofen THEDES remained a liquid at room temperature, with no evidence of phase separation or deposition (Fig. 1).

\subsection{Thermal properties}

A DSC analysis of the 3:1 menthol:ibuprofen THEDES was performed, as well as for the individual components. In the thermogram of menthol (Fig. 2), two asymmetric peaks corresponding to melting are observed, yielding melting temperatures $\left(T_{\mathrm{m}}\right)$ of 29 and $35^{\circ} \mathrm{C}$, in good agreement with data from Corvis et al. (2012). The two melting peaks are result from the presence of two polymorphs of racemic menthol, $\alpha$ and $\beta$ (Corvis et al., 2012). The crystallization temperature $\left(T_{\mathrm{c}}\right)$ is observed at $16^{\circ} \mathrm{C}$ in the first scan (run 1) and in subsequent scans is located at $6^{\circ} \mathrm{C}$.

In the thermogram of ibuprofen (Fig. 3 ), in the first heating scan (run2) melting is observed with $T_{\mathrm{m}}$ of $77^{\circ} \mathrm{C}$, which is in good agreement with the literature (Dudognon et al., 2008). This peak is no longer observed in subsequent scans, indicating that the sample did not undergo recrystallization, remaining fully amorphous. This can be confirmed by the detection of a glass transition, with a glass transition temperature $\left(T_{\mathrm{g}}\right)$ located at $-41^{\circ} \mathrm{C}$, close to the $T_{\mathrm{g}}$ value reported in literature (Bras et al., 2008).

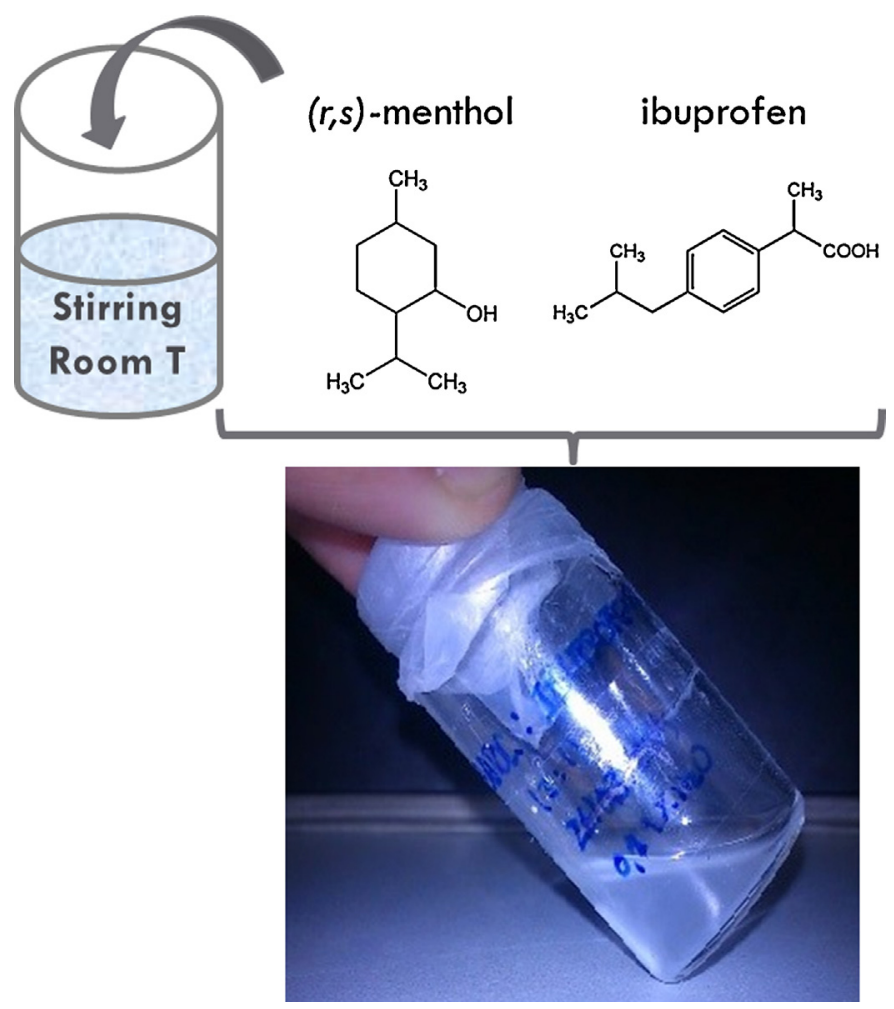

Fig. 1. Schematic of the preparation of 3:1 menthol:ibuprofen THEDES. The final mixture is liquid at room temperature.

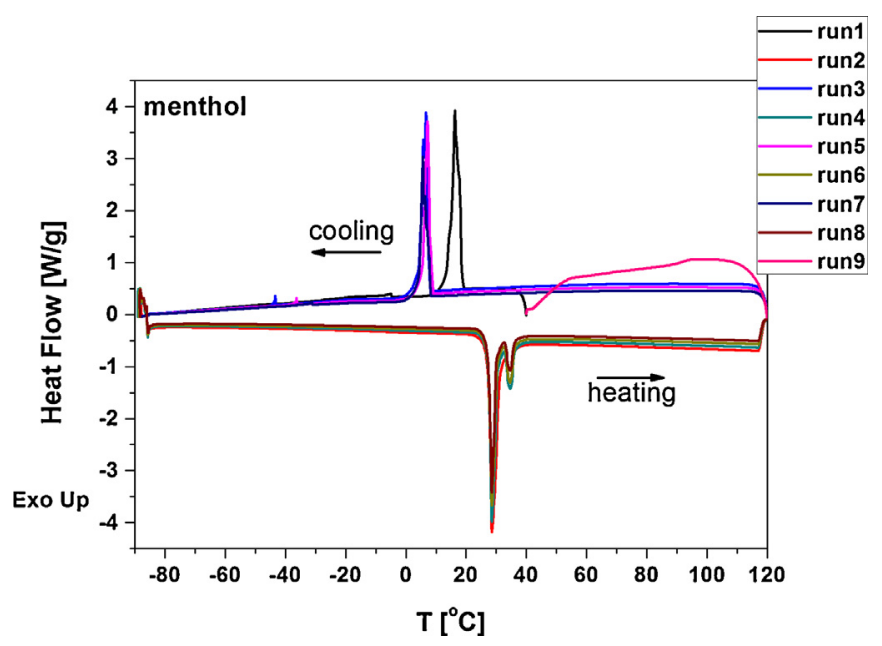

Fig. 2. DSC thermogram of racemic menthol used in the preparation of $3: 1$ menthol:ibuprofen THEDES.

From the thermograms of 3:1 menthol:ibuprofen, shown in Fig. 4, it is clear that the thermal behavior of THEDES is different from the behavior of the individual components.

The only thermal event detected in successive scans is the glass transition, which occurs with a mid-point temperature at $-50.1^{\circ} \mathrm{C}$ (Table 1). This presents evidence that the material is fully amorphous from the moment it is prepared, remaining stable after successive thermal treatment cycles, provided that maximum temperature remains below $100^{\circ} \mathrm{C}$, at which the sample degrades. The lowering of $T_{\mathrm{g}}$ provides evidence of interactions established between menthol and ibuprofen, which make the THEDES behave like a different entity. 


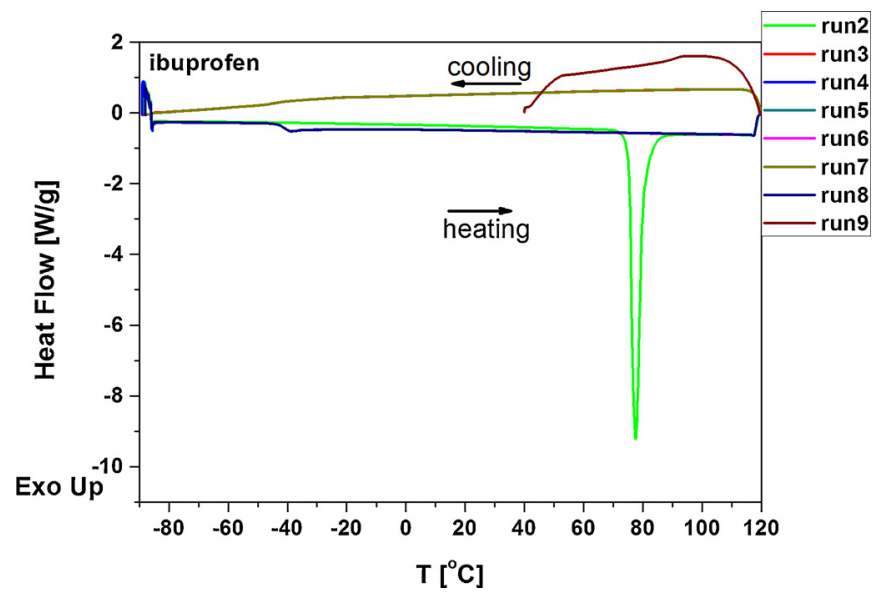

Fig. 3. DSC thermogram of ibuprofen used in the preparation of $3: 1$ menthol: ibuprofen THEDES.

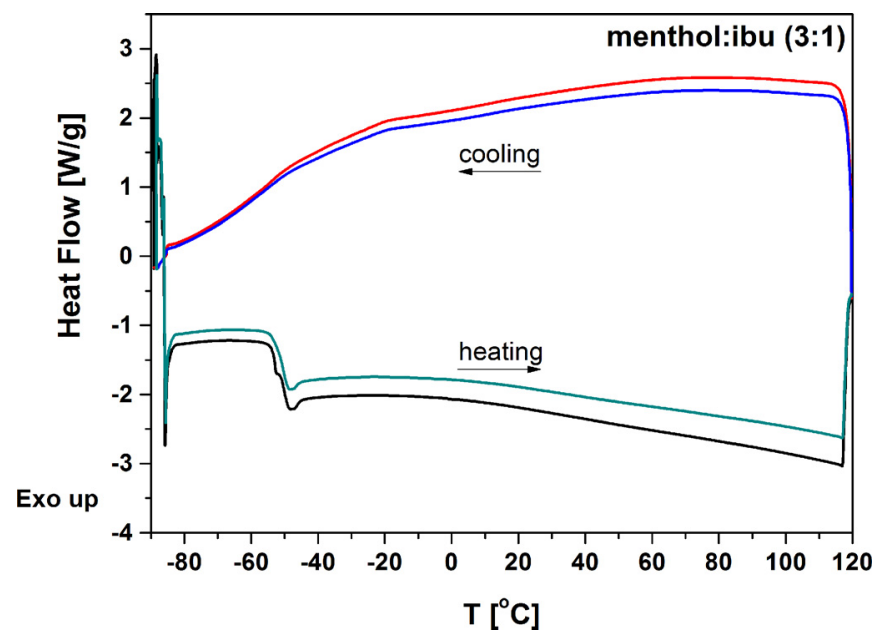

Fig. 4. DSC thermogram of 3:1 menthol:ibuprofen THEDES.

Table 1

Experimental data obtained from DSC analysis for menthol, ibuprofen and 3:1 menthol:ibuprofen THEDES (taken at mid-point, in the first DSC run).

\begin{tabular}{llll}
\hline Sample & $T_{\mathrm{g}}\left({ }^{\circ} \mathrm{C}\right)$ & $T_{\mathrm{C}}\left({ }^{\circ} \mathrm{C}\right)$ & $T_{\mathrm{m}}\left({ }^{\circ} \mathrm{C}\right)$ \\
\hline Menthol & - & 16 & 29,35 \\
Ibuprofen & -41 & - & 77 \\
3:1 menthol:ibuprofen & -50.1 & - & - \\
\hline
\end{tabular}

\subsubsection{Dissolution studies}

Different studies in the literature report the permeation of THEDES through a membrane (Marques et al., 2002; Stott et al., 1998). Nonetheless the dissolution profile of the THEDES in comparison with that of the active pharmaceutical ingredient (API) has not been discussed. Differences would be expected as the API is in different forms, in the THEDES ibuprofen is in the liquid state while the pure API is in the powder form. It is known that, various factors affect the dissolution of an API, namely drug crystallinity, polymorphism, solubility and particle size, among others (Williams et al., 2013). For this reason it is important to compare the dissolution profile of ibuprofen, the model NSAID used in this work, in powder form and in the eutectic mixture, as shown in Fig. 5. The figure gives the percentage of drug release, $M_{\mathrm{t}} / M_{\mathrm{inf}}$, where $M_{\mathrm{t}}$ corresponds to the mass of ibuprofen in solution

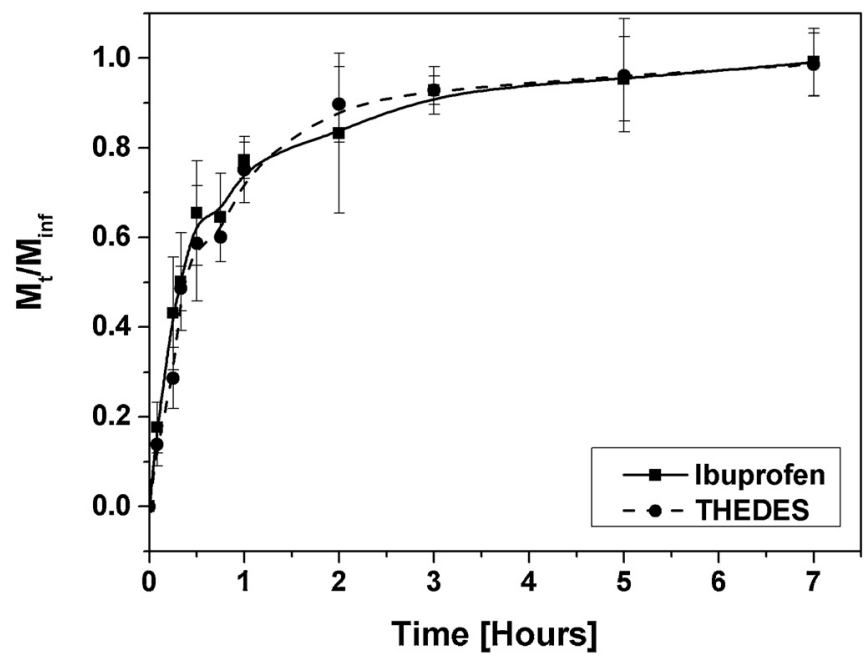

Fig. 5. Dissolution profile of ibuprofen in powder form and in the $3: 1$ menthol: ibuprofen THEDES.

measured at time $t$, and $M_{\text {inf }}$ is the mass of ibuprofen in solution upon complete solubilisation.

From Fig. 5 it can be observed that ibuprofen in the THEDES has a similar dissolution profile than pure ibuprofen. This may indicate that the interactions established between menthol and ibuprofen upon THEDES formation are disrupted when the THEDES is in aqueous solution. The dissolution profiles allow the calculation of the dissolution efficiency, which is a parameter conventionally used to characterize pharmaceutical dosage forms (Costa et al., 2001). The dissolution efficiency is defined as the ratio between the integral of percentage of drug released until time $t$ and the integral of $100 \%$ drug dissolution at the same time $t$ (Eq. (1)):

Dissolution efficiency $=\frac{\int_{0}^{t} \frac{M t}{M \text { inf }} \times \mathrm{d} t}{\int_{0}^{t} 1 \times \mathrm{d} t} \times 100$

After $7 \mathrm{~h}$ the dissolution efficiency for pure ibuprofen and for ibuprofen from the THEDES was similar and close to $86 \%$.

\subsection{Supercritical sintering}

The development of suitable carriers for active agents is an important field of research in pharmaceutical applications. In this work we have prepared 3D structures of an SPCL polymer blend doped with THEDES via supercritical fluid sintering. A sample of SPCL and a sample of SPCL loaded with ibuprofen were used as control, as stated previously.

The thermal behavior of SPCL has been reported previously and reveals the presence of a melting peak at $60^{\circ} \mathrm{C}$, corresponding to the PCL part of the blend, while no additional thermal events are observed in the range $-150-200^{\circ} \mathrm{C}$ (Craveiro et al., 2014). For this reason, the temperature chosen for supercritical sintering of the matrices was $50^{\circ} \mathrm{C}$.

The 3D structures obtained are highly porous and when these were impregnated with THEDES no excess liquid was observed on the surface of the matrices.

\subsection{Morphological analysis}

The morphological analysis of the matrices prepared was performed by SEM and micro-CT. Fig. 6 presents the SEM and micro-CT images of the cross-section cuts of the structures. MicroCT analysis allows the visualization of the three cross-sectional 

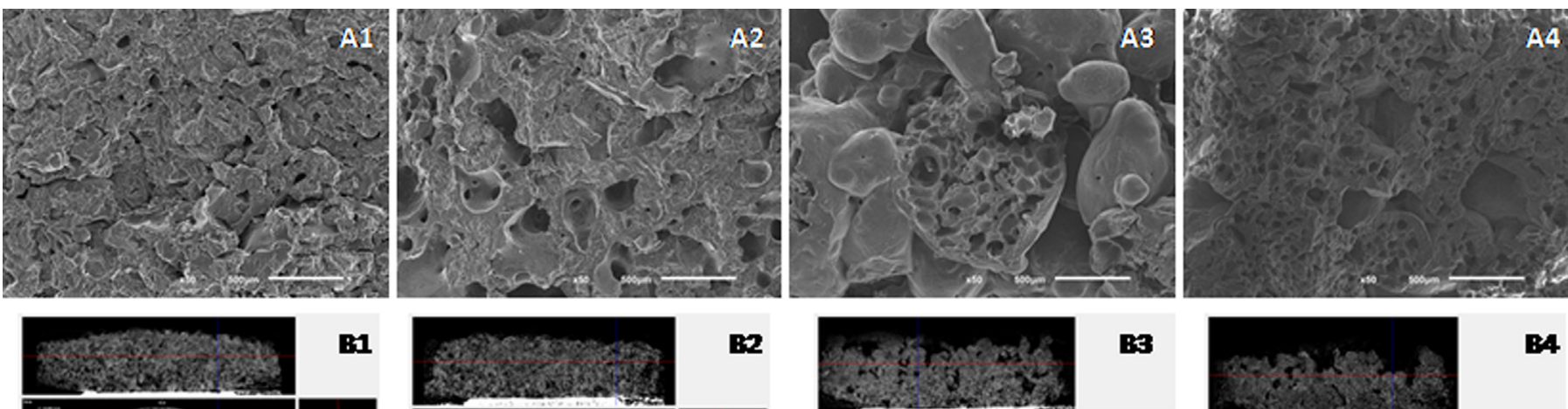

B1
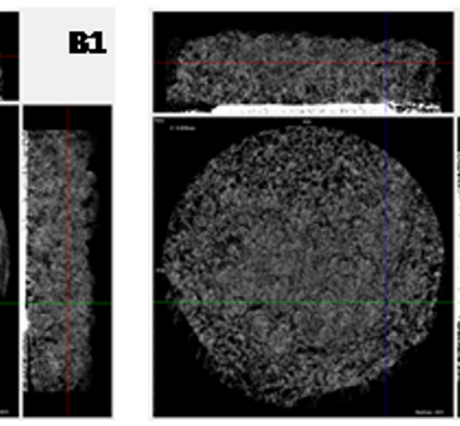

B2

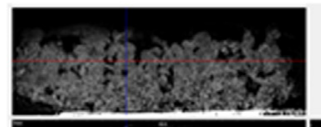

:3
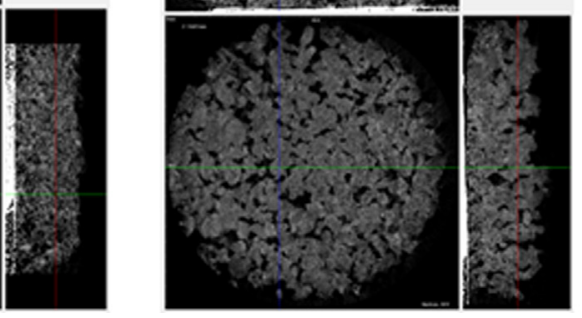

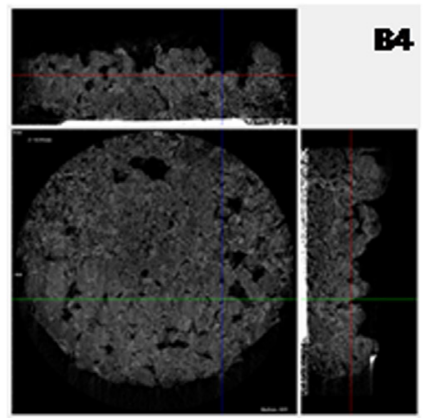

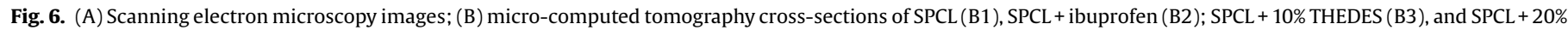
THEDES (B4).

axes of the samples, providing additional information on the anisotropy of the structures.

From the images it can be observed that the presence of the THEDES enhanced the formation of a more open structure with higher porosity and interconnectivity. Additionally, micro-CT allows the quantification of the morphological parameters of the matrices prepared, which are summarized in Table 2. Pore size distribution was also studied and the results are presented in Fig. 7.

Despite the fact that the average pore size is similar in all matrices, the values of porosity and interconnectivity present some differences, and confirm the SEM results showing an increase of $31 \%$ in porosity and $25 \%$ in interconnectivity between SPCL and SPCL impregnated with 20\% THEDES. The matrices loaded with the same mass of ibuprofen (SPCL + ibuprofen, and SPCL + 10\% THEDES) have similar morphological properties. Being a liquid, THEDES contributes to the aggregation of the polymer particles in larger agglomerates that will sinter upon exposure to $\mathrm{scCO}_{2}$ and will contribute to a higher porosity and interconnectivity. This effect is more pronounced for higher amounts of THEDES; as observed. These differences may play an important role in the role of the structure as a controlled drug delivery carrier. The morphological properties of the 3D architecture, namely parameters such as porosity and interconnectivity will contribute to the tortuosity of the system which is a feature that will, on its turn, influence the release of the active compounds.

\subsection{Release studies}

The performance of the matrices prepared was tested in vitro in PBS, an isotonic solution, for 21 days. Release studies were conducted and the cumulative mass release of ibuprofen was recorded, as shown in Fig. 8. The concentration in solution, or the

\section{Table 2}

Morphological parameters of 3D structures prepared by supercritical fluid sintering.

\begin{tabular}{llc}
\hline & Porosity (\%) & Interconnectivity (\%) \\
\hline SPCL & 13 & 3 \\
SPCL + ibuprofen & 23 & 8 \\
SPCL + 10\% THEDES & 17 & 7 \\
SPCL + 20\% THEDES & 44 & 28 \\
\hline
\end{tabular}

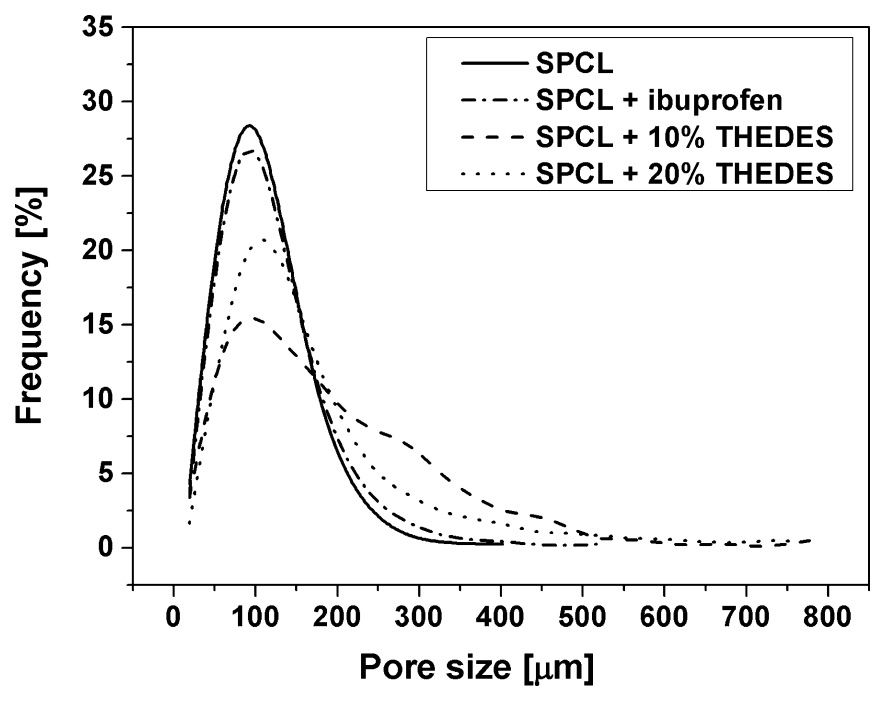

Fig. 7. Pore size distribution of the matrices prepared using supercritical fluid sintering.

cumulative mass of drug released, is higher in the case of SPCL $+20 \%$ THEDES, as expected. It is interesting to notice the differences observed between the polymeric matrixes loaded with the same amount of ibuprofen (SPCL + ibuprofen and SPCL + 10\% THEDES). Although the dissolution profile of pure ibuprofen was similar to the dissolution profile of ibuprofen in THEDES (Fig. 5), ibuprofen presents a faster release from the polymeric carrier impregnated with THEDES than from the SPCL + ibuprofen matrix (Fig. 8).

Fig. 8 shows $M_{\mathrm{t}} / M_{\text {inf }}$ as a function of time, which allows a more objective comparison of the rate of release and the mechanisms that underlie the release profile. As regards the percentage of ibuprofen released, SPCL + ibuprofen and SPCL + THEDES matrices present similar profiles, with SPCL $+10 \%$ THEDES having a faster release of ibuprofen to the solution. The morphological properties of the matrices, especially porosity and interconnectivity, play an important role in the water uptake of the structures, the swelling 


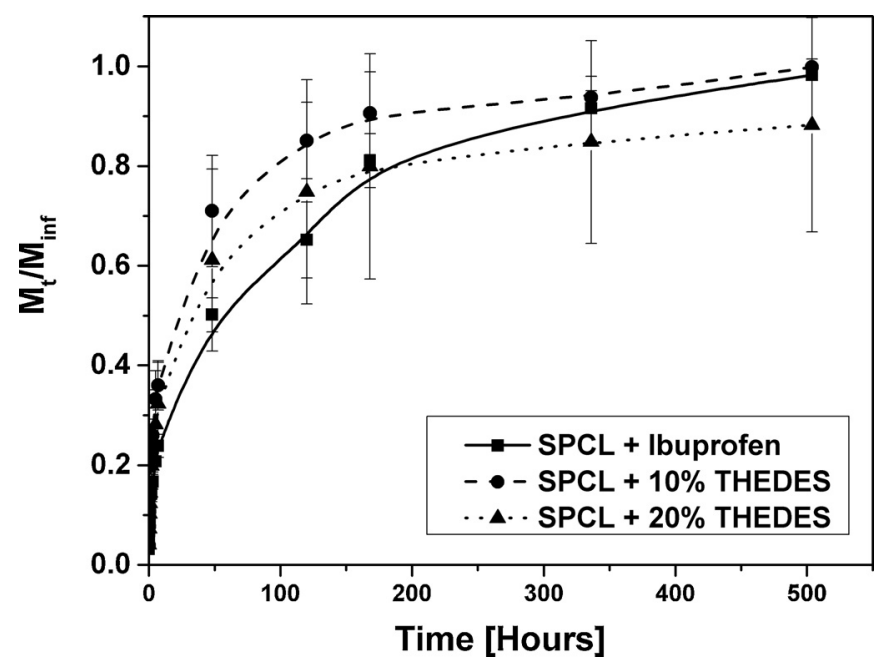

Fig. 8. Percentage of ibuprofen released from $S P C L+$ ibuprofen, $S P C L+10 \%$ THEDES and SPCL $+20 \%$ THEDES matrices.

and the diffusion of the active compounds from the bulk of the matrix to the solution (Siepmann and Peppas, 2001). The fact that THEDES is in the liquid form, together with the higher porosity of the matrices, may help to understand this behavior. Nonetheless, matrices loaded with ibuprofen and 10\% THEDES have similar morphological characteristics and SPCL $+10 \%$ THEDES has a faster release rate. On the other hand, for the same time period studied the sample SPCL $+20 \%$ THEDES released $80 \%$ of the ibuprofen loaded. The release of the sample with 20\% THEDES did not reach $100 \%$ during the time frame evaluated, which may be due to diffusion constrictions of the active compound from the core of the matrix to the media.

After 21 days, the $\mathrm{pH}$ of the samples was measured and it was observed that the $\mathrm{pH}$ decreased to 7.02 in the case of SPCL (used as control), to 6.56 in the case of SPCL + ibuprofen (mixture of the two powders also used as control), to 6.70 for SPCL $+10 \%$ THEDES, and to 6.46 for SPCL $+20 \%$ THEDES.

The mathematical modeling of the release of THEDES from the polymeric matrix can further elucidate the mechanisms governing the release. Several empirical and semi-empirical mathematical models have been derived from Fick's law of diffusion (Costa et al., 2001; Siepmann and Gopferich, 2001; Siepmann and Peppas, 2001). The Korsmeyer-Peppas model is a semi-empirical model which can be used to relate the amount of drug released with time when the release deviates from the purely Fickian diffusion (Costa et al., 2001; Siepmann and Peppas, 2011).

This model relies, however, on several assumptions that cannot be disregarded. This model assumes that the diffusion is one dimensional, the swelling is negligible, the diffusivity is constant and the release experiments were carried out under sink conditions, i.e., the equilibrium was not altered throughout the duration of the experiment (Siepmann and Peppas, 2011). At these conditions, can be applied to the systems studied:

Table 3

Release exponent and kinetic constant of the release systems prepared.

\begin{tabular}{llll}
\hline Sample & $n$ & $k$ & $R^{2}$ \\
\hline SPCL + ibuprofen & 0.41 & 0.099 & 0.9955 \\
SPCL + 10\% THEDES & 0.46 & 0.147 & 0.9835 \\
SPCL + 20\% THEDES & 0.46 & 0.137 & 0.9960 \\
\hline
\end{tabular}

$\frac{M t}{M_{\text {inf }}}=K t^{n}$

$k$ is the kinetic constant and $n$ is the release exponent, which is characteristic of the drug release mechanism. The linearity of this equation can only be verified up to $60 \%$ of the total amount of drug $M_{\text {inf. Table }} 3$ presents the values of the parameters calculated.

The correlation coefficient obtained for the fit of the KorsmeyerPeppas model to the experimental release data for all three formulations indicates that this semi-empirical model is able to accurately predict the mechanism of ibuprofen release from the SPCL matrix. The release exponent $(n)$, which is nearly 0.45 , indicates that the diffusion of the drug out of the matrices, considered as cylinders, is the mechanism that governs the release (Siepmann and Peppas, 2001). SPCL is mostly hydrophobic with low swelling ability, and therefore this effect was not anticipated.

The values of the kinetics constants calculated $(k)$ for the different matrices evidence a steeper initial slope for the matrices loaded with THEDES. For the initial time points the diffusion of ibuprofen from the liquid THEDES promotes a faster release rate. Despite the fact that the solubility profile of solid form of ibuprofen and the liquid form of THEDES give a similar profile (Fig. 5), when impregnated in a 3D matrix the liquid form presents a faster diffusion and therefore an enhanced delivery rate. Complementary information can though be taken from the data obtained. Depending on the application it is possible to tune the release profile of the active compound by changing its physical state from solid to liquid and incorporating it in a polymeric delivery system.

\section{Conclusions}

In this work we have developed a delivery system for therapeutic deep eutectic solvents (THEDES), namely for 3:1 menthol:ibuprofen. Supercritical fluid sintering was used to prepared 3D porous structures impregnated with THEDES. The results demonstrate that the solubility profiles of ibuprofen in powder form and in THEDES in PBS are similar, nonetheless, when they are incorporated in a matrix the liquid form has a faster release profile. The drug release in this system is mostly governed by diffusion, as expected due to the hydrophobic nature of the polymer used as carrier. The outcomes of this work prove, hereafter, the feasibility to couple green technologies for the development of enhanced biomaterials for pharmaceutical applications.

\section{Acknowledgements}

Rita Craveiro, Alexandre Paiva and Ângelo Rocha are grateful for financial support from Fundação para a Ciência e a Tecnologia (FCT) through the grants PTDC/EQU-EPR/12191/2010/ENIGMA, SFRH/ $\mathrm{BPD} / 44946 / 2008$ and SFRH/BD/93049/2013. The research leading to these results has received funding from through the projects ENIGMA - PTDC/EQU-EPR/121491/2010, PTDC/QUI-QUI/119210/ 2010, PTDC/EQU-EQU/122106/2010, PEst-C/EQB/LA0006/2013 from the European Union's Seventh Framework Programme (FP7/2007-2013) under grant agreement $n^{\circ}$ REGPOT - CT2012316331-POLARIS and from Project "Novel smart and biomimetic materials for innovative regenerative medicine approaches (Ref.: RL1 - ABMR - NORTE-01-0124-FEDER-000016)" co-financed by North Portugal Regional Operational Programme (ON.2-O Novo Norte), under the National Strategic Reference Framework (NSRF), through the European Regional Development Fund (ERDF). 


\section{References}

Abbott, A.P., Boothby, D., Capper, G., Davies, D.L., Rasheed, R.K., 2004. Deep eutectic solvents formed between choline chloride and carboxylic acids: versatile alternatives to ionic liquids. J. Am. Chem. Soc. 126, 9142-9147.

Alves, A., Duarte, A.R.C., Mano, J.F., Sousa, R.A., Reis, R.L., 2012. PDLLA enriched with ulvan particles as a novel 3D porous scaffold targeted for bone engineering. J. Supercrit. Fluids 65, 32-38.

Balmayor, E.R., Feichtinger, G.A., Azevedo, H.S., van Griensven, M., Reis, R.L., 2009. Starch-poly- $N$-caprolactone Microparticles Reduce the Needed Amount of BMP-2. Clin. Orthop. Relat. Res. 467, 3138-3148.

Bhamidipati, M., Sridharan, B., Scurto, A.M., Detamore, M.S., 2013. Subcritical $\mathrm{CO}_{2}$ sintering of microspheres of different polymeric materials to fabricate scaffolds for tissue engineering. Mater. Sci. Eng. C 33, 4892-4899.

Bica, K., Rodriguez, H., Gurau, G., Cojocaru, O.A., Riisager, A., Fehrmann, R., Rogers, R. D., 2012. Pharmaceutically active ionic liquids with solids handling, enhanced thermal stability, and fast release. Chem. Commun. 48, 5422-5424.

Bras, A.R., Noronha, J.P., Antunes, A.M.M., Cardoso, M.M., Schonhals, A., Affouard, F., Dionisio, M., Correia, N.T., 2008. Molecular motions in amorphous ibuprofen as studied by broadband dielectric spectroscopy. J. Phys. Chem. B 112, 1108711099.

Carriazo, D., Serrano, M.C., Gutierrez, M.C., Ferrer, M.L., del Monte, F., 2012. Deepeutectic solvents playing multiple roles in the synthesis of polymers and related materials. Chem. Soc. Rev. 41, 4996-5014.

Corvis, Y., Negrier, P., Massip, S., Leger, J.M., Espeau, P., 2012. Insights into the crysta structure, polymorphism and thermal behavior of menthol optical isomers and racemates. Crystengcomm 14, 7055-7064.

Costa, P., Manuel, J., Lobo, S., 2001. Modeling and comparison of dissolution profiles. Eur. J. Pharm. Sci. 13, 123-133.

Craveiro, R., Martins, M., Santos, G.B., Correia, N., Dionisio, M., Barreiros, S., Duarte A.R.C., Reis, R.L., Paiva, A., 2014. Starch-based polymer-IL composites formed by compression moulding and supercritical fluid foaming for self-supported conductive materials. RSC Adv. 4, 17161-17170.

Dai, Y.T., van Spronsen, J., Witkamp, G.J., Verpoorte, R., Choi, Y.H., 2013. Natural deep eutectic solvents as new potential media for green technology. Anal. Chim. Acta $766,61-68$.

Duarte, A.R.C., Mano, J.F., Reis, R.L., 2009a. Dexamethasone-loaded scaffolds prepared by supercritical-assisted phase inversion. Acta Biomater. 5, 2054 2062.

Duarte, A.R.C., Mano, J.F., Reis, R.L., 2009b. Supercritical fluids in biomedical and tissue engineering applications: a review. Int. Mater. Rev. 54, 214-222.

Duarte, A.R.C., Santo, V.E., Alves, A., Siiva, S.S., Moreira-Silva, J., Silva, T.H., Marques, A.P., Sousa, R.A., Gomes, M.E., Mano, J.F., Reis, R.L., 2013. Unleashing the potential of supercritical fluids for polymer processing in tissue engineering and regenerative medicine. J. Supercrit. Fluid 79, 177-185.

Dudognon, E., Danede, F., Descamps, M., Correia, N.T., 2008. Evidence for a new crystalline phase of racemic ibuprofen. Pharm. Res.-Dord 25, 2853-2858.

Knez, Z., Markocic, E., Novak, Z., Hrncic, M.K., 2011. Processing polymeric biomaterials using Supercritical $\mathrm{CO}_{2}$. Chem. Ing. Tech. 83, 1371-1380.

Lu, D.R., Xiao, C.M., Xu, S.J., 2009. Starch-based completely biodegradable polymer materials. Express Polym. Lett. 3, 366-375.
Malafaya, P.B., Silva, G.A., Reis, R.L., 2007. Natural-origin polymers as carriers and scaffolds for biomolecules and cell delivery in tissue engineering applications. Adv. Drug Deliv. Rev. 59, 207-233.

Mano, J.F., Silva, G.A., Azevedo, H.S., Malafaya, P.B., Sousa, R.A., Silva, S.S., Boesel, L.F., Oliveira, J.M., Santos, T.C., Marques, A.P., Neves, N.M., Reis, R.L., 2007. Natural origin biodegradable systems in tissue engineering and regenerative medicine: present status and some moving trends. J. Royal Soc. Inter. 4, 999-1030.

Marques, A.P., Reis, R.L., Hunt, J.A., 2002. The biocompatibility of novel starch-based polymers and composites: in vitro studies. Biomaterials 23, 1471-1478.

Morrison, H.G., Sun, C.C., Neervannan, S., 2009. Characterization of thermal behavior of deep eutectic solvents and their potential as drug solubilization vehicles. Int. J. Pharm. 378, 136-139.

Paiva, A., Craveiro, R., Aroso, I., Martins, M., Reis, R.L., Duarte, A.R.C., 2014. Natural deep eutectic solvents-solvents for the 21st century. Acs. Sustain. Chem. Eng. 2, 1063-1071.

Pena-Pereira, F., Namiesnik, J., 2014. Ionic liquids and deep eutectic mixtures: sustainable solvents for extraction processes. Chemsuschem 7, 1784-1800.

Reis, A.V., Guilherme, M.R., Moia, T.A., Mattoso, L.H.C., Muniz, E.C., Tambourgi, E.B., 2008. Synthesis and characterization of a starch-modified hydrogel as potential carrier for drug delivery system. J. Polym. Sci. Pol. Chem. 46, 2567-2574.

Russ, C., Konig, B., 2012. Low melting mixtures in organic synthesis - an alternative to ionic liquids? Green Chem. 14, 2969-2982.

Salerno, A., Pascual, C.D., 2015. Bio-based polymers, supercritical fluids and tissue engineering. Process Biochem. 50, 826-838.

Siepmann, J., Gopferich, A., 2001. Mathematical modeling of bioerodible, polymeric drug delivery systems. Adv. Drug Deliv. Rev. 48, 229-247.

Siepmann, J., Peppas, N.A., 2001. Modeling of drug release from delivery systems based on hydroxypropyl methylcellulose (HPMC). Adv. Drug. Deliv. Rev. 48, 139157.

Siepmann, J., Peppas, N.A., 2011. Higuchi equation: derivation, applications, use and misuse. Int. J. Pharm. 418, 6-12.

Silva, G.A., Costa, F.J., Neves, N.M., Reis, R.L., 2004. Microparticulate release systems based on natural origin materials. Adv. Exp. Med. Biol. 553, 283-300.

Singh, M., Sandhu, B., Scurto, A., Berkland, C., Detamore, M.S., 2010. Microspherebased scaffolds for cartilage tissue engineering: using subcritical $\mathrm{CO}_{2}$ as a sintering agent. Acta Biomater. 6, 137-143.

Stott, P.W., Williams, A.C., Barry, B.W., 1998. Transdermal delivery from eutectic systems: enhanced permeation of a model drug, ibuprofen. J. Controlled Release 50, 297-308.

Tuntarawongsa, S., Phaechamud, T., 2012a. Menthol, borneol, camphor and WS-3 eutectic mixture. Biomater. Appl. 506, 355-358.

Tuntarawongsa, S., Phaechamud, T., 2012b. Polymeric eutectic system. Adv. Mater. Res. Switz 528, 180-183.

Wang, H., Gurau, G., Shamshina, J., Cojocaru, O.A., Janikowski, J., MacFarlane, D.R., Davis, J.H., Rogers, R.D., 2014. Simultaneous membrane transport of two active pharmaceutical ingredients by charge assisted hydrogen bond complex formation. Chem. Sci. 5, 3449-3456.

Williams, H.D., Trevaskis, N.L., Charman, S.A., Shanker, R.M., Charman, W.N., Pouton, C.W., Porter, C.J.H., 2013. Strategies to address low drug solubility in discovery and development. Pharmacol. Rev. 65, 315-499.

Zhang, A.J., Zhang, Q.K., Bai, H., Li, L., Li, J., 2014. Polymeric nanoporous materials fabricated with supercritical $\mathrm{CO}_{2}$ and $\mathrm{CO}_{2}$-expanded liquids. Chem. Soc. Rev. 43, 6938-6953. 